\title{
Serum levels of soluble interleukin-2 receptor in association with oxidative stress index in patients with different types of HPV
}

\author{
Cenk Nayki ${ }^{1}$, Murat Gunay ${ }^{2}$, Mehmet Kulhan ${ }^{1}$, Umit Nayki ${ }^{1}$, \\ Murat Cankaya ${ }^{3}$, Nur Gozde Kulhan ${ }^{4}$ \\ ${ }^{1}$ Erzincan University, Medical Faculty, Department of Obstetrics and Gynecology, Erzincan, Turkey \\ ${ }^{2}$ Erzincan Univeristy, Medical Faculty, Department of Biochemistry, Erzincan, Turkey \\ ${ }^{3}$ Erzincan University, Science and Art Faculty, Department of Biology, Erzincan, Turkey \\ ${ }^{4}$ Mengucek Gazi Training and Research Hospital, Department of Obstetrics and Gynecology, Erzincan, Turkey
}

\begin{abstract}
Objectives: The aim of this paper is to determine the oxidative-antioxidative status and levels of soluble interleukin-2 receptor (SIL-2R) in serum of patients with different types of HPV infections and to compare it with patients who are negative for HPV. Material and methods: A total of 80 women were divided into three groups as follows: Group 1 consisted of 25 women who were positive for HPV types 16 or 18 ; Group 2 consisted of 25 women who were positive for other types of HPV including type $31,33,35,39,45,51,52,56,58,59$ or 68 ; Group 3 consisted of 30 patients who were negative for HPV as a control group. Serum sIL-2R and plasma oxidative stress index (OSI) were analyzed.

Results: Serum sIL-2R levels were significantly higher in group 1 compared to group 2 and 3. OSI was found significantly increased in groups 1 and 2 compared to group 3. Also, we found a weak positive correlation between IL-2R and OSI.

Conclusion: sIL-2R and oxidative stress may have a role in HPV infection, especially in case of high-risk types.
\end{abstract}

Key words: human papillomavirus, total oxidant status, total antioxidant capacity, soluble interleukin-2 receptor

Ginekologia Polska 2017; 88, 7: 355-359

\section{INTRODUCTION}

Human papillomavirus (HPV) is commonly observed in sexually active individuals. HPV infection can be asymptomatic, can induce genital warts, or can result in cervical precancerous changes leading to cancer [1]. It is clinically important because of its relationship with cervical cancer. HPV can be clinically classified as "low-risk" and "high-risk" depending on the relative propensity of the HPV-associated lesions to undergo malignant progression. HPV 16 is the most prevalent high-risk HPV type, followed by HPV 18 and others [2]. High-risk HPV types are associated with precancerous lesions such as cervical dysplasia or cervical squamous intraepithelial lesions (SIL) leading to cervical cancer. However, not all infections with low-risk or high-risk types of HPV usually result in cervical disease [3]. The majority of
HPV infections is subclinical and transient (80\%) and in most of the cases they resolve spontaneously through effective immune response that eliminates virus or suppresses it to low undetectable levels [4].

In fact, neoplastic growth is an inappropriate outcome in the natural history of HPV, and a number of other events have to concur to induce the transformation of viral infection into a neoplastic lesion. Hence, a number of viral, host and environmental co-factors have been proposed as potential candidates [5]. Among them, oxidative stress and dysfunctional immune response are of particular interest to us.

Oxidative stress is a condition arising from an increased production of reactive oxygen species (ROS) associated with a decreased antioxidant capability of the cell. ROS are constantly generated in aerobic cells during normal physio- 
logical processes, as well as during a number of processes including infections and inflammation [6].

Studies suggest that a host immune response to HPV is critical for effective control of HPV infection $[7,8]$. It has been postulated that the cellular immune response, as opposed to the humoral response, plays a critical role in eliminating HPV [8].

Cytokines are pleiotropic glycoproteins that regulate biological activities such as cell survival, proliferation, differentiation and activation, at both local and systemic levels. During inflammation, their excessive release may lead to both chronicity and pathogenicity. In this context, increased levels of sIL-2R are known to be a proxy for general immune activation. It is expressed in various cell populations including activated Th1 and Th2 cells [9]. Levels of sIL-2R can be measured easily because a part of it is proteolytically cleaved and is found in serum [10]. Previous studies have demonstrated elevated serum levels of sIL-2R in various autoimmune disorders such as rheumatoid arthritis, systemic lupus erythematosus or Kawasaki disease, among transplant recipients who subsequently reject their graft, and in individuals with viral infections, including HIV and hepatitis, or hematological and lung tumors, as well as precancer and cancer of the uterine cervix [11-18].

Based on the data about the ability of a woman to respond to HPV infection and to produce cytokines that preferentially activate cell-mediated responses in association with oxidative stress, measurement of a specific cytokine would be a useful marker of adequate immune response to HPV.Thus, in the present study, we aim to determine the oxidative-antioxidative status and levels of sIL-2R in serum of patients with different types of HPV, which we compare with controls who are negative for HPV.

\section{MATERIAL AND METHODS}

This cross-sectional study consisted of 80 sexually active women who were admitted to the Gynecology Department of Erzincan University Mengucek Gazi Training and Research Hospital for a routine control. Subjects were questioned about socioeconomic, demographic, sexual, reproductive, medical and smoking history. Women were at age between 30-45 and had regular menstrual cycles. A pelvic examination including visual inspection, bimanual and ultrasonographic evaluation was performed to all patients. In addition to a cervical smear obtained with a cytobrush (ecto and endocervical), HPV DNA testing was conducted on specimen transport medium (STM) samples using the Hybrid Capture tube test (Digene Corp.) formatted to detect $13 \mathrm{HPV}$ types $(16,18,31,33,35,39,45,51,52,56,58,59$ and 68) [19]. Pap smears were classified according to the 2001 Bethesda system of reporting for cervical cytology [20]. All of the subjects were cytologically normal (Bethesda Class 1) with no concomitant other genital infection or history of precancerous cervical lesion and cervical cancer at the time of enrollment into the cohort. Other exclusion criteria applied were: smoking, use of any contraceptive medication, having multiple sexual partners, having any infection of genitourinary system or anywhere else such as upper respiratory system within three months before the study and history of any malignancy. All of the patients positive for HPV were asymptomatic. Subjects were divided into three groups as follows: Group 1 consisted of 25 women who were positive for HPV types 16 or 18 ; Group 2 consisted of 25 women who were positive for the other types of HPV including types $31,33,35,39,45,51,52,56,58,59$ or 68 ; Group 3 consisted of 30 patients who were negative for HPV as control. The patients who were diagnosed as positive for HPV infection underwent colposcopic evaluation and upon unremarkable findings were enrolled into the study. The study was approved by the Ethics Committee of Erzincan University and a written informed consent was obtained from each patient. All procedures performed in this study were in accordance with ethical standards of institutional and/or national research committee and with the 1964 Helsinki declaration and its later amendments or comparable ethical standards.

A total of $10 \mathrm{~mL}$ of peripheral venous blood was taken for assessment of IL-2R, total oxidant status (TOS), total antioxidant capacity (TAC) and oxidative stress index (OSI). Within half an hour, the blood samples were centrifuged at $3000 \mathrm{rpm}$ and the serum was kept at $-80^{\circ} \mathrm{C}$ until assayed.

SIL-2R levels were measured by chemiluminescent immunometric assay technique using a commercial kit (IL-2R for use on IMMULITE 2000 systems, Siemens Healthcare, Diagnostics Products Ltd., UK). Result were presented as U/mL.

Plasma TOS was measured using a novel automated colorimetric measurement method developed by Erel [21]. According to this method, oxidants present in the sample oxidized the ferrous ion-o-dianisidine complex to a ferric ion. The oxidation reaction was enhanced by glycerol molecules, which were abundant in the reaction medium. The ferric ion together with xylenol orange in an acidic medium gives a colored complex. The color intensity measured spectrophotometrically is related to the total amount of oxidant molecules present in the sample. The assay was calibrated with hydrogen peroxide and the results were expressed in terms of micromolar hydrogen peroxide equivalent per liter ( $\left.\mu \mathrm{mol} \mathrm{H}_{2} \mathrm{O}_{2} \mathrm{Eq} / \mathrm{L}\right)$.

TAC of plasma was measured using a novel automated colorimetric measurement method developed by Erel [22]. This method involves the production of the most potent biological radical - the hydroxyl radical with Fenton reaction to interact with a colorless substrate being O-dianisidine to produce the dianisyl radical, which is bright yellowish-brown in color. Upon the addition of a plasma sample, the oxida- 
tive reactions initiated by the hydroxyl radicals are being suppressed by the antioxidant components of the plasma, preventing the color change and thereby providing an effective measurement of TAC. The assay results were expressed as mmol Trolox Eq/L.

The ratio ofTOS to TAC is accepted as the oxidative stress index (OSI), and the OSI value was calculated according to the following formula [23]:

OSI (arbitrary unit) $=\mathrm{TOS}\left(\mu \mathrm{mol} \mathrm{H}_{2} \mathrm{O}_{2} \mathrm{Eq} / \mathrm{L}\right) / \mathrm{TAC}(\mathrm{mmol}$ Trolox Eq/L).

The statistical analysis was performed using the Statistical Package for the Social Sciences version 22 (SPSS Inc., Chicago, IL, USA). Results were expressed as mean \pm standard error (SE). ANOVA and Kruskal-Wallis tests were used to analyze the differences among groups. The correlation between IL-2R and OSI were analyzed by Pearson correlation test. Statistical significance was set at $\mathrm{p}<0.05$.

\section{RESULTS}

Some demographic and reproductive characteristics are presented in Table 1. The differences between groups for age, gravidity, parity, number of abortions, age at menarche and age at first coitus were not statistically significant.

Serum sIL-2R levels were significantly higher in group 1 than in group 2 and $3(p<0.001)$. There was no statistically significant difference among groups for plasma TAC. However, TOS and OSI were found to be significantly increased in group 1 and 2 compared to group $3(p=0.013$ and $p=0.001$,

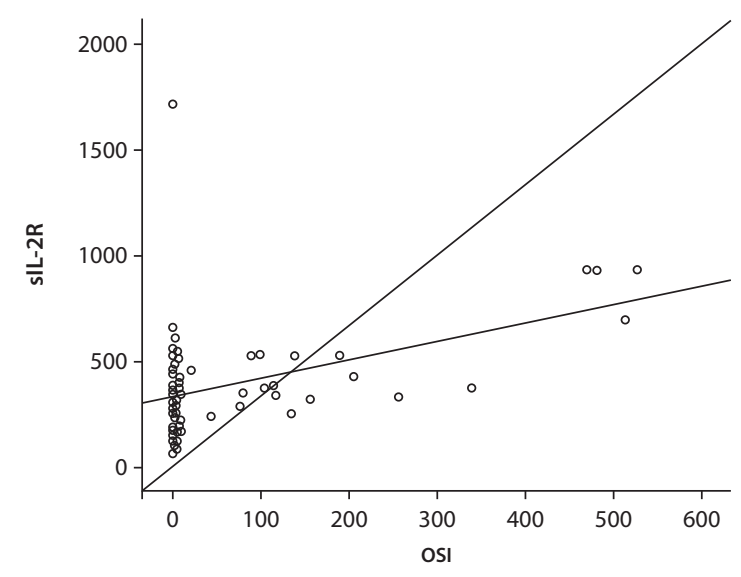

Figure 1. The weak positive correlation between sIL-2R and OSI, considering the HPV status of the patients

respectively) (Table 2 ). Additionally, we found a weak positive correlation between IL-2R and OSI $(r=0.326, p<0.003)$ (Figure 1).

\section{DISCUSSION}

Persistent infection of the cervix with a high risk HPV in association with co-factors required for the malignancy progression, leads to cervical cancer. Oxidative stress is one of the co-factors receiving great interest for its role during the progression of neoplasia. Oxidative status has been reported altered in blood of patients with cervical intraepithelial neoplasia (CIN). Studies on serum of patients

Table 1. Some demographic and reproductive characteristics of the patients

\begin{tabular}{|c|c|c|c|}
\hline & $\begin{array}{l}\text { Group } 1 \\
(n=25)\end{array}$ & $\begin{array}{l}\text { Group } 2 \\
(n=25)\end{array}$ & $\begin{array}{l}\text { Group } 3 \\
(n=30)\end{array}$ \\
\hline Age (year)* & $37.04 \pm 4.6$ & $36.72 \pm 4.5$ & $36.90 \pm 4.3$ \\
\hline Gravidity** & 2 & 3 & 3 \\
\hline Parity $^{* *}$ & 2 & 2 & 2 \\
\hline Abortus* & 0 & 0 & 0 \\
\hline Age at menarche (year)* & $12.00 \pm 0.9$ & $12.24 \pm 0.9$ & $12.33 \pm 0.8$ \\
\hline Age at first coitus* & $22.36 \pm 2.8$ & $22.88 \pm 3.1$ & $22.03 \pm 4.5$ \\
\hline
\end{tabular}

*Data is presented as mean $\pm \mathrm{SE}$ (standard error)

${ }^{*}$ Data is presented as median

\section{Table 2. Evaluation of IL2R, TOS, TAC and OSI in patients}

\begin{tabular}{|c|c|c|c|c|}
\hline & $\begin{array}{l}\text { Patients with HPV types } 16,18 \\
\qquad(n=25)\end{array}$ & $\begin{array}{l}\text { Patients with other types of HPV } \\
\qquad(n=25)\end{array}$ & $\begin{array}{l}\text { Patients negative for HPV } \\
\qquad(\mathrm{n}=30)\end{array}$ & $\mathbf{P}$ \\
\hline sIL-2R [U/mL]* & $391.3 \pm 306.6$ & $353.8 \pm 191.8$ & $282.3 \pm 246.5$ & $<0.001$ \\
\hline $\operatorname{TOS}\left[\mu \mathrm{mol} \mathrm{H}_{2} \mathrm{O} \mathrm{Eq} / \mathrm{L}\right]^{* *}$ & $137.2 \pm 55.4$ & $61.5 \pm 17.2$ & $4.1 \pm 0.6$ & 0.013 \\
\hline TAC [mmol Trolox Eq/L] $]^{* *}$ & $1.05 \pm 0.06$ & $1.15 \pm 0.065$ & $1.148 \pm 0.12$ & 0.718 \\
\hline OSI** & $120.4 \pm 37.9$ & $48.7 \pm 12.9$ & $3.9 \pm 0.5$ & 0.001 \\
\hline
\end{tabular}

*Data is presented as median \pm interquartile range

${ }^{* *}$ Data is presented as mean $\pm \mathrm{SE}$ (standard error) 
with CIN and carcinoma of the cervix showed alterations in lipid peroxidation and impairment of antioxidant systems, either enzymatic or not [24, 25]. Additionally, other blood indicators of oxidative stress such as TBARS, ALA-D reactivation index, and vitamin C content were reported altered (increased or decreased) in both low-grade and high-grade SIL, as well as cervical cancer [26]. In the present study, we found serum TOS and OSI to be significantly increased in patients with HPV type 16 and 18 compared to patients with other types of HPV and to patients who were negative for HPV. Our results are consistent with the literature in some parts.

There are numerous studies on cytokines and markers of immune response to HPV infection in the literature. Many of the authors have evaluated immune markers that were locally secreted in the cervix, tissue-based immune markers or immune response by patient-derived peripheral blood mononuclear cells (PBMCs) [27-30]. However, data concerning infection-related immune response in either plasma or serum is limited.

Previous studies have suggested that sIL-2R levels offer a rapid, reliable and noninvasive measure of disease activity, response to therapy and, in some cases, prognosis in a broad spectrum of conditions associated with T- or B-cell immune activation [11]. Similarly, sIL-2R levels have been evaluated in gynecologic conditions such as endometriosis, cervical cancer in association with HPV and in other genital cancers [31-33]. For example, Koumantakis et al. reported that serum SIL-2R levels, as well as IL-6 and IL-1a levels, were higher in women with endometriosis [33]. In another study, changes in serum sIL-2R levels were found to be correlated with ovarian cancer and it was suggested that serial sIL-2R measurement may be used in monitoring the disease course in patients with ovarian cancer [34]. On the other hand, Ferdeghini et al. noticed that sIL-2R in serum was the most sensitive antigen for endometrial cancer, thus it could be used as a tumor marker for the management of these patients [32].

In this study, we have found serum levels of IL2R to be significantly increased in patients with HPV type 16 and 18. In fact, Hildesheim et al. were the first to use plasma to evaluate immunity in HPV infection. However, their comparison of carcinogenic HPV-positive women with low-grade lesions to carcinogenic HPV-negative women with low-grade lesions failed to find a statistical difference in sIL-2R [35]. In contrast, Bais et al. measured numerous cytokines such as IL-2, IL-4, IL-10, IL-12, IFN- $\gamma$ and TNF- $\alpha$ in plasma and reported that high-risk HPV infection was associated with higher mean plasma IL-2 levels [36]. Moreover, the results of the study by Gupta et al. revealed that serum IL-2 and sIL-2R levels were significantly higher in patients diagnosed with cervical intraepithelial neoplasm or invasive cervical cancer and indicated a host-vested cellular impairment in women with precancerous or cancerous lesions of the cervix [31].
Although results of Pardo-Govea et al. were consistent with such findings, they stated that type Th1 immune response prevails in patients with cervical precancerous lesions, whether HPV positive or not [37]. On the other hand, a different study suggested that sIL-2R levels are most likely a marker of response to the events of infection and cancerous invasion rather than a marker of a host immune response that predicts the risk of progression from LSIL to HSIL [10].

The present study has several limitations. First of all, this is a cross-sectional study with a small sample size. We have evaluated the serum levels of sIL-2R only while analyzing it in both serum and cervical tissue might lead to more stable results. Also, we did not evaluate serum sIL-2R levels by individual HPV type. Since the immune response may vary by HPV type, the levels should be considered individually [38]. On the other hand, we did not consider several factors related to HPV persistence and clearance that are documented in the literature and include menopausal status, smoking, oral contraceptive use or concomitant sexually transmitted disease, all of which may confound the results. In contrast to other studies, we kept cervical precancer and cancer patients out of the study population. We considered only patients with HPV infection that was limited to cervix. Also, we evaluated immunity in association with oxidative-antioxidative status. In this regard, we found a weak correlation between sIL-2R and OSI.

In conclusion, the measurements of serum or plasma cytokines, soluble immune markers and indicators of oxidative-antioxidative status have been the center of attention in recent years with the hope it would provide useful diagnostic and prognostic information, and also insight to the pathogenesis of numerous diseases. In this regard, our results point to a possible role of SIL-2R and oxidative stress in HPV infection and also may provide an insight into the clinical usefulness of both sIL2R and OSI in patients infected with high-risk types of HPV. However, larger prospective studies are needed to reach for more accurate results and for more conclusions.

\section{Conflict of interest}

Authors declared no conflicts of interest related to this study.

\section{REFERENCES}

1. Wright TC, Richart RM. Role of human papillomavirus in the pathogenesis of genital tract warts and cancer. Gynecol Oncol. 1990; 37(2): 151-164, indexed in Pubmed: 2160903.

2. Nygård $M$, Hansen BoT, Dillner J, et al. Targeting human papillomavirus to reduce the burden of cervical, vulvar and vaginal cancer and pre-invasive neoplasia: establishing the baseline for surveillance. PLoS One. 2014; 9(2): e88323, doi: 10.1371/journal.pone.0088323, indexed in Pubmed: 24505474

3. Trottier H, Franco EL. The epidemiology of genital human papillomavirus infection. Vaccine. 2006; 24 Suppl 1: S1-15, doi: 10.1016/j.vaccine.2005.09.054, indexed in Pubmed: 16406226. 
4. Narisawa-Saito M, KiyonoT. Basic mechanisms of high-risk human papillomavirus-induced carcinogenesis: roles of E6 and E7 proteins. Cancer Sci. 2007; 98(10): 1505-1511, doi: 10.1111/j.1349-7006.2007.00546.x, indexed in Pubmed: 17645777.

5. Senapati R, Senapati NN, Dwibedi B. Molecular mechanisms of HPV mediated neoplastic progression. Infect Agent Cancer. 2016; 11: 59, doi: 10.1186/s13027-016-0107-4, indexed in Pubmed: 27933097.

6. Poljsak B, Šuput D, Milisav I. Achieving the balance between ROS and antioxidants: when to use the synthetic antioxidants. Oxid Med Cell Longev. 2013; 2013: 956792, doi: 10.1155/2013/956792, indexed in Pubmed: 23738047.

7. Frazer IH, Tindle RW. Cell-mediated immunity to papillomaviruses. Papillomavirus Report. 1992; 3: 52-58.

8. Edwards RP, Kuykendall K, Crowley-Nowick P, et al.T lymphocytes infiltrating advanced grades of cervical neoplasia. CD8-positive cells are recruited to invasion. Cancer. 1995; 76(8): 1411-1415, indexed in Pubmed: 8620416.

9. Rubin LA, Nelson DL. The soluble interleukin-2 receptor: biology, function, and clinical application. Ann Intern Med. 1990; 113(8): 245-250, doi: 10.7326/0003-4819-113-8-619.

10. Ung A, Kramer TR, Schiffman M, et al. Soluble interleukin 2 receptor levels and cervical neoplasia: results from a population-based case-control study in Costa Rica. Cancer Epidemiol Biomarkers Prev. 1999; 8(3): 249-253, indexed in Pubmed: 10090303.

11. Semenzato G, Bambara LM, Biasi D, et al. Increased serum levels of soluble interleukin-2 receptor in patients with systemic lupus erythematosus and rheumatoid arthritis. J Clin Immunol. 1988; 8(6): 447-452, indexed in Pubmed: 3065351.

12. van Steenbergen HW, van Nies JAB, Ruyssen-Witrand A, et al. IL2RA is associated with persistence of rheumatoid arthritis. Arthritis Res Ther. 2015; 17: 244, doi: 10.1186/s13075-015-0739-6, indexed in Pubmed: 26350950.

13. Teraura $\mathrm{H}$, Kotani $\mathrm{K}$, Minami $\mathrm{T}$, et al. The serum concentration of soluble interleukin-2 receptor in patients with Kawasaki disease. Ann Clin Biochem. 2017; 54(2): 209-213, doi: 10.1177/0004563216677583, indexed in Pubmed: 28081636.

14. Nakamura $Y$, Tanaka $Y$, Tanaka $M$, et al. Soluble interleukin-2 receptor index predicts the development of acute graft-versus-host disease after allogeneic hematopoietic stem cell transplantation from unrelated donors. Int J Hematol. 2016; 103(4): 436-443, doi: 10.1007/s12185-0161936-z, indexed in Pubmed: 26791380.

15. Kloster BE, John PA, Miller LE, et al. Soluble interleukin 2 receptors are elevated in patients with AIDS or at risk of developing AIDS. Clin Immunol Immunopathol. 1987; 45(3): 440-446, indexed in Pubmed: 3119265.

16. Gupta M, Stenson M, O'Byrne $M$, et al. Comprehensive serum cytokine analysis identifies IL-1RA and soluble IL-2Ra as predictors of event-free survival in T-cell lymphoma. Ann Oncol. 2016; 27(1): 165-172, doi: 10.1093/annonc/mdv486, indexed in Pubmed: 26487586.

17. Naumnik W, Chyczewska E, Kovalchuk O, et al. The clinical significance of serum soluble interleukin 2 receptor (sIL-2R) concentration in lung cancer. Folia Histochem Cytobiol. 2001; 39 Suppl 2: 185-186, indexed in Pubmed: 11820599.

18. Clerici $M$, Merola $M$, Ferrario $E$, et al. Cytokine production patterns in cervical intraepithelial neoplasia: association with human papillomavirus infection. J Natl Cancer Inst. 1997; 89(3): 245-250, indexed in Pubmed: 9017005

19. Khunamornpong S, Settakorn J, Sukpan K, et al. Performance of HPV DNA testing with hybrid capture 2 in triaging women with minor cervical cytologic abnormalities (ASC-US/LSIL) in Northern Thailand. Asian Pac J Cancer Prev. 2014; 15(24): 10961-10966, indexed in Pubmed: 25605209

20. Verma I, Jain V, Kaur T. Application of bethesda system for cervical cytology in unhealthy cervix. J Clin Diagn Res. 2014; 8(9): OC26-OC30, doi: 10.7860/JCDR/2014/9620.4893, indexed in Pubmed: 25386491.

21. Erel O. A new automated colorimetric method for measuring total oxidant status. Clin Biochem. 2005; 38(12): 1103-1111, doi: 10.1016/j. clinbiochem.2005.08.008, indexed in Pubmed: 16214125.
22. Erel O. A novel automated method to measure total antioxidant response against potent free radical reactions. Clin Biochem. 2004; 37(2): 112-119, indexed in Pubmed: 14725941.

23. Demirbag R, Yilmaz R, Erel O, et al. The relationship between potency of oxidative stress and severity of dilated cardiomyopathy. Can J Cardiol. 2005; 21(10): 851-855, indexed in Pubmed: 16107908.

24. Looi ML, Mohd Dali AZ, Md Ali SA, et al. Oxidative damage and antioxidant status in patients with cervical intraepithelial neoplasia and carcinoma of the cervix. Eur J Cancer Prev. 2008; 17(6): 555-560, doi: 10.1097/CEJ.0b013e328305a10b, indexed in Pubmed: 18941377.

25. Kim SY, Kim JW, Ko YS, et al. Changes in lipid peroxidation and antioxidant trace elements in serum of women with cervical intraepithelial neoplasia and invasive cancer. Nutr Cancer. 2003; 47(2): 126-130, doi: 10.1207/s15327914nc4702_3, indexed in Pubmed: 15087263.

26. Gonçalves TL, Erthal F, Corte CLD, et al. Involvement of oxidative stress in the pre-malignant and malignant states of cervical cancer in women. Clin Biochem. 2005; 38(12): 1071-1075, doi: 10.1016/j.clinbiochem.2005.09.008, indexed in Pubmed: 16269141.

27. Marks MA, Viscidi RP, Chang $K$, et al. Differences in the concentration and correlation of cervical immune markers among HPV positive and negative perimenopausal women. Cytokine. 2011; 56(3): 798-803, doi: 10.1016/j.cyto.2011.09.012, indexed in Pubmed: 22015106.

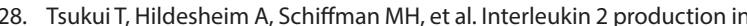
vitro by peripheral lymphocytes in response to human papillomavirus-derived peptides: correlation with cervical pathology. Cancer Res. 1996; 56(17): 3967-3974, indexed in Pubmed: 8752165.

29. Sharma A, Rajappa M, Saxena A, et al. Cytokine profile in Indian women with cervical intraepithelial neoplasia and cancer cervix. Int J Gynecol Cancer. 2007; 17(4): 879-885, doi: 10.1111/j.1525-1438.2007.00883.x, indexed in Pubmed: 17343606.

30. Kovacic MB, Katki HA, Kreimer AR, et al. Epidemiologic analysis of histologic cervical inflammation: relationship to human papillomavirus infections. Hum Pathol. 2008; 39(7): 1088-1095, doi: 10.1016/j.humpath.2007.12.002, indexed in Pubmed: 18495212.

31. Gupta MM, Jain R, Parashari A, et al. Circulating immune profile in patients with pre-cancer and cancer of the cervix: a cross sectional study among Indian women. Bull Cancer. 1993; 80(10): 852-856, indexed in Pubmed: 8204922.

32. Ferdeghini M, Gadducci A, Prontera C, et al. Serum soluble interleukin-2 receptor (sIL-2R) assay in cervical and endometrial cancer. Preliminary data. Anticancer Res. 1993; 13(3): 709-713, indexed in Pubmed: 8317901.

33. Koumantakis E, Matalliotakis I, Neonaki M, et al. Soluble serum interleukin-2 receptor, interleukin- 6 and interleukin- $1 \mathrm{a}$ in patients with endometriosis and in controls. Arch Gynecol Obstet. 1994; 255(3): 107-112, indexed in Pubmed: 7979562.

34. Gadducci A, Ferdeghini M, Malagnino G, et al. Elevated serum levels of neopterin and soluble interleukin-2 receptor in patients with ovarian cancer. Gynecol Oncol. 1994; 52(3): 386-391, doi: 10.1006/gyno.1994.1066.

35. Hildesheim A, Schiffman MH, Tsukui T, et al. Immune activation in cervical neoplasia: cross-sectional association between plasma soluble interleukin 2 receptor levels and disease. Cancer Epidemiol Biomarkers Prev. 1997; 6(10): 807-813, indexed in Pubmed: 9332763.

36. Bais AG, Beckmann I, Lindemans J, et al. A shift to a peripheral Th2-type cytokine pattern during the carcinogenesis of cervical cancer becomes manifest in CIN III lesions. J Clin Pathol. 2005; 58(10): 1096-1100, doi: 10.1136/jcp.2004.025072, indexed in Pubmed: 16189158.

37. Pardo-Govea T, Callejas D, Núñez-Troconis J, et al. [Gamma interferon (IFN-gamma), tumor necrosis factor alpha (TNF-alpha) and interleukins 2, 4 and 6 (IL-2, IL-4, IL-6) in cervical-uterine cells of intraepithelial neoplasia: a preliminary report]. Invest Clin. 2005; 46(1): 5-13, indexed in Pubmed: 15782532.

38. Kovacic MB, Katki HA, Kreimer AR, et al. Epidemiologic analysis of histologic cervical inflammation: relationship to human papillomavirus infections. Hum Pathol. 2008; 39(7): 1088-1095, doi: 10.1016/j.humpath.2007.12.002, indexed in Pubmed: 18495212. 